\title{
Evaluation of Uncertainty in Temporal Waveforms of Microwave Transistors
}

\author{
Gustavo Avolio, Member, IEEE, Antonio Raffo, Member, IEEE, Jeffrey Jargon, Senior Member, \\ IEEE, Paul D. Hale, Fellow, IEEE, Dominique M. M.-P. Schreurs, Fellow, IEEE, \\ Dylan F. Williams, Fellow, IEEE
}

\begin{abstract}
We evaluate the uncertainty in on-wafer vectorcalibrated nonlinear measurements with the National Institute of Standards and Technology (NIST) Microwave Uncertainty Framework. We include in our analysis uncertainties in the passive calibration standards, power meter, NIST-traceable phase calibration reference, cable bending, and probe alignment. These uncertainties are propagated first to the electrical quantities across the terminals of the device-under-test, which was an on-wafer microwave transistor. Next, we propagate uncertainties to the transistor current-generator plane, whose temporal voltage/current waveforms and impedances are of interest for the design of power amplifiers.
\end{abstract}

Index Terms- Microwave transistors, microwave measurements uncertainty, nonlinear de-embedding, vectorcalibrated nonlinear measurements.

\section{INTRODUCTION}

$\mathrm{M}$ uch progress has been made in large-signal network analysis in the last two decades [1]-[6]. Systems like the LSNA enable the acquisition of the vector calibrated timedomain waveforms at the terminals of a transistor at microwave frequencies. These systems can be used for characterization, modeling, and waveform engineering.

One crucial step when dealing with microwave measurement systems is the calibration, which removes most of the systematic errors introduced by the measurement system itself. Nevertheless, residual uncertainties in the calibration procedure, still exist and become significant as the measurement frequency increases. These uncertainties originate, for instance, from imperfections in the calibration standards.

Much work has been devoted to the uncertainty evaluation in measurements at microwave and millimeter-wave frequencies, including [7]-[13]. In [7]-[11] uncertainty is evaluated in microwave small-signal measurements. In [12], [13] the study of uncertainty is carried out for load-pull measurements. Nevertheless, [12] and [13] focus on scalar quantities such as gain and output power.

Manuscript received This work was supported by FWO Vlaanderen (Belgium)

G. Avolio and D. M. M.-P Schreurs are with KU Leuven, B-3001 Leuven, Belgium (e-mail: gustavo.avolio@esat.kuleuven.be).

A. Raffo is with University of Ferrara, 44122 Ferrara, Italy.

D. F. Williams, P.D. Hale, and J. Jargon are with the National Institute of Standards and Technology, Boulder, Colorado, USA.
Here we evaluate residual calibration uncertainties in onwafer vector-calibrated large-signal measurements performed with a mixer-based large-signal network analyzer (LSNA). We account in this work for uncertainties in the relative calibration, absolute calibration, cable bending, and probe alignment. We propagated these uncertainties first to the waves across the transistor terminals. Furthermore, we shifted the uncertainties to the transistor current-generator plane, whose electrical quantities are of great interest for the design of power amplifiers.

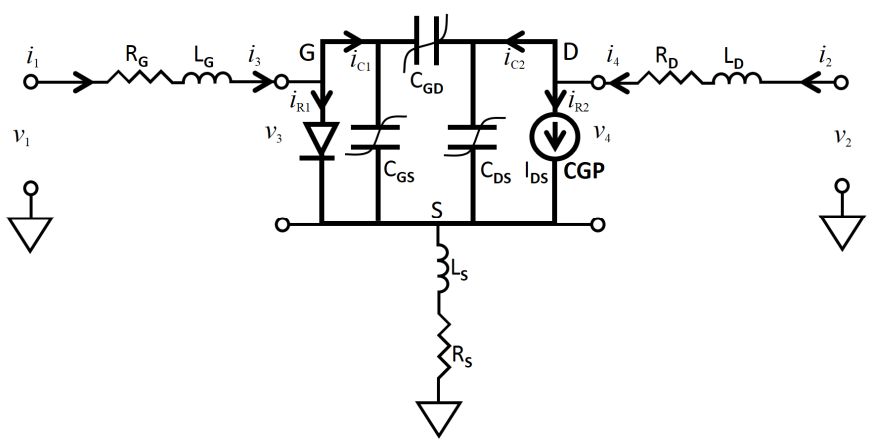

Fig. 1. Simplified nonlinear model for a field-effect transistor. 'CGP' indicates the current-generator plane. $v_{1}, i_{1}, v_{2}$, and $i_{2}$ are the voltages and current at the transistor terminals.

\section{Motivation}

Knowledge of the temporal current and voltage at the transistor current-generator plane (see Fig. 1) is crucial in order to perform waveform engineering, which is a useful tool for the design of power amplifiers [14]. The various classes of operation of power amplifiers are defined by the shape of these waveforms across the transistor's current-generator plane [15], [16].

Waveform engineering can be performed in different ways. One approach consists of starting from a model of the transistor current source and using this model to generate the desired time-domain domain waveforms in a simulation environment [17]. Alternatively, one can directly measure the voltages and currents at the desired operating frequency [14]. The latter approach is preferred in many situations, as the extraction of an accurate nonlinear model for the transistor current source, including trapping and thermal effects [18], may not be a straightforward task.

Starting from measurements one can search for the operating condition that yields the desired performance and, based on the experimental voltage and current waveforms, 
determine the impedances needed at the transistor terminals. As long as the design frequency is low enough to neglect the transistor's parasitic elements and the transistor's nonlinear capacitances, the measured time-domain waveforms are very close to those appearing at the current-generator plane. Therefore the selected impedances, obtained directly from measurements, guarantee the desired class of operation.

However, this assumption may not be valid at microwave frequencies. The measured current and voltage waveforms, along with the corresponding impedances, may differ from those at the current-generator plane as they are distorted by both the parasitics and the transistor's nonlinear capacitances. In this situation one needs to determine the electrical quantities at the current-generator plane starting from timedomain waveforms measured at microwave frequencies. Thus, a nonlinear de-embedding procedure is needed in order to determine the impedances at the current-generator plane [19][21] based on microwave nonlinear measurements.

Nonlinear de-embedding relies on direct characterization of the linear parasitic network associated with transistor layout and access structures, and of the transistor's intrinsic nonlinear capacitances. Once these are determined, one can obtain the actual voltages and currents at the current-generator plane corresponding to those measured at microwave frequencies. However, no study has been performed yet to estimate the uncertainty in the current and voltage time-domain waveforms and impedances obtained after nonlinear de-embedding.

In this work, we propagate residual uncertainties to the electrical quantities at the transistor current-generator plane as illustrated in Fig. 2. Starting from on-wafer raw LSNA measurements, we propagate uncertainties firstly through the calibration algorithm. Next, we propagate uncertainties through the nonlinear de-embedding algorithm.

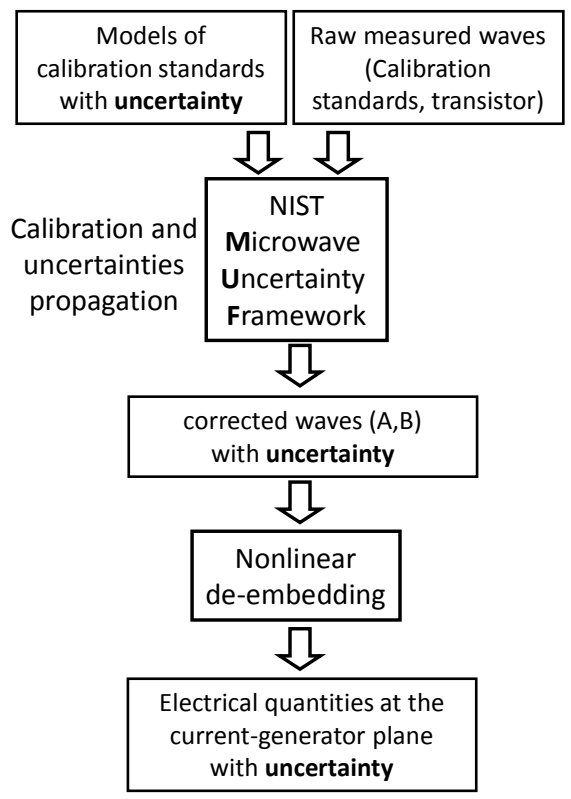

Fig. 2. Calibration and nonlinear de-embedding procedure.

\section{CALIBRATION}

\section{A. Nominal calibration}

We performed the calibration with the NIST Microwave Uncertainty Framework* ${ }^{*}$ The Microwave Uncertainty Framework supports several calibration algorithms [22] and allows one to propagate residual uncertainties to the calibrated device-under-test (DUT) S-parameters and traveling waves, and to quantities derived from them. [7], [23].

We calibrated raw waves acquired with a $50 \mathrm{GHz}$ LSNA as illustrated in Fig. 3. The calibration grid was defined with the fundamental frequency $\mathrm{f}_{0}$ equal to $5 \mathrm{GHz}$ and eight harmonics. The resolution bandwidth (IF bandwidth) was set to $1 \mathrm{~Hz}$. The error-boxes in Fig. $3 \mathrm{~b}$ are described in terms of S-parameters but other description could be adopted [4]. In Fig. 3 the raw waves, as measured by the LSNA receivers, are $a_{1 m}, b_{1 m}, a_{2 m}$, and $b_{2 m}$. The corrected waves at the transistor terminals are $a_{5}$, $b_{5}, a_{6}, b_{6}$ and are used to derive $i_{1}, v_{1}, i_{2}$, and $v_{2}$ in Fig. 1 are derived. As shown in Fig. 3a, we performed a two-tier calibration.

The first-tier is split into two parts, as typically done for LSNA measurements [4]. A relative calibration determines the reflection terms of the error-boxes and the product of the transmission terms [22].

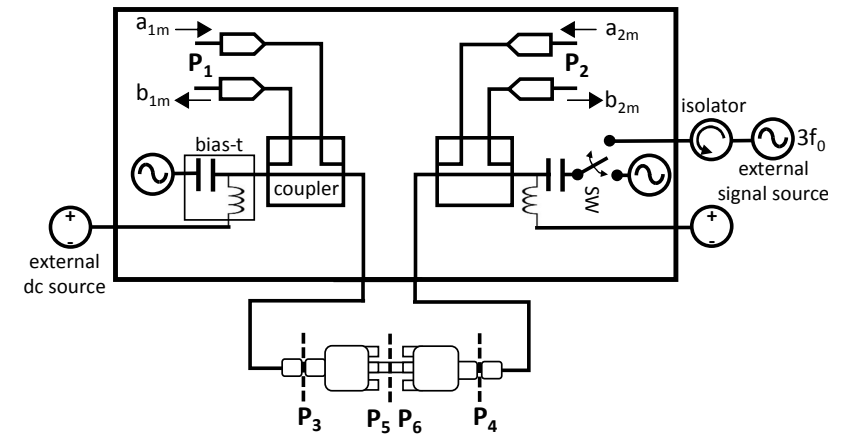

(a)

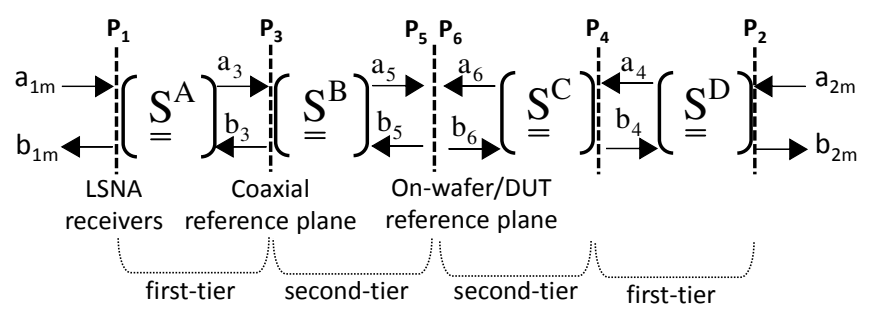

(b)

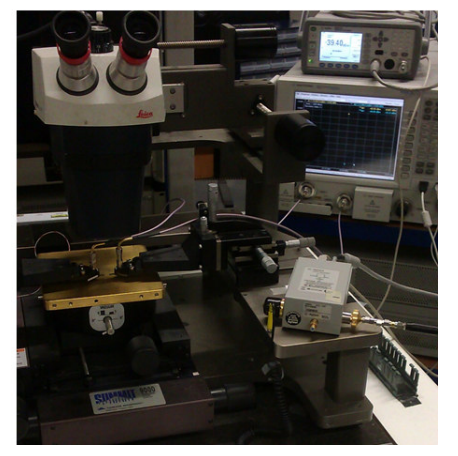

${ }^{*}$ [Online]. Available at http://www.nist.gov/ctl/rf-technology/relatedsoftware.cfm 
(c)

Fig. 3. (a) Simplified measurement set-up and (b) calibration model in terms of error boxes. In (a) the switch SW is connected to the internal source during the calibration. During the measurements with the transistor it is connected to an external signal source to perform active load-pull. In (c) a mixer-based LSNA set-up ${ }^{\dagger}$.

The actual value of the transmission terms is determined by the absolute calibration which consists of connecting a power and phase reference at $\mathrm{P}_{3}$ in Fig. 3b [2], [4], [24].

The second-tier calibration was performed directly on wafer and we used a multiline TRL algorithm [25]-[27].

Here we summarize the measurements steps:

1. Raw waves were acquired while connecting one-port standards (i.e., Short, Open, and Load) and a transmission standard (Thru) at $\mathrm{P}_{3}$ and $\mathrm{P}_{4}$;

2. Raw waves were acquired while connecting a power sensor and a phase reference at $\mathrm{P}_{3}$;

3. Raw waves were acquired while probing on-wafer calibration standards;

4. Raw waves were acquired while probing the transistor;

5. Raw waves were calibrated with the NIST Microwave Uncertainty Framework.

\section{B. Calibration with uncertainty evaluation}

The NIST Microwave Uncertainty Framework propagates uncertainty through each calibration step. We included in our analysis uncertainties in the passive calibration standards, power meter, NIST-traceable phase calibration reference, cable bending, and probe alignment. We neglected the uncertainties in the measured raw waves due to noise of the high-dynamic range receivers of the mixer-based LSNA [28].

Also, in order to account for any drift occurring during the measurement period, we acquired the measurements of the calibration standards before and after the transistor measurements. We performed the calibration with the Microwave Uncertainty Framework twice and averaged the two calibrations.

We developed physical models of the passive calibration standards and estimated the uncertainties in the models elements from mechanical tolerances from the manufacturer [29].

In Tables I-II we report the error mechanisms included within the calibration and their uncertainties.

The values of the physical dimensions of the on-wafer transmission lines and their uncertainties are estimated from the foundry process datasheet.

We accounted for probe-alignment errors with a model available in the NIST Microwave Uncertainty Framework.

To characterize the impact of cable bending, we measured a thru line in its relaxed state, and then remeasured it as we bent the cable in a similar way to what we do in practice. In this way we were able to include uncertainties in cable bending in our experiments based on direct measurements.

The comb-generator was characterized at NIST with a

† Trade names are used here only to fully specify the experimental configuration and do not constitute an endorsement by NIST. Other instruments made by the same or different manufacturer may function as well or better for this application sampling oscilloscope [30], [31] and uncertainty propagated in its phase spectrum. The uncertainty in the comb-generator phase at the frequencies of our calibration grid is reported in Table III.

For the amplitude calibration we included errors in the power-meter measurements. We included the following errors, as defined in [32]: the reference oscillator mismatch, the reference oscillator power uncertainty, the zero-set error, the zero carryover error, and the instrumentation error, and error in the power sensor calibration factor. Typical values for these errors can be found in manufacturer's documentation [32]. We also measured the input match of the power sensor with a calibrated VNA and used it in the amplitude calibration procedure.

TABLE I

STANDARDS USED FOR THE SOLT CALIBRATION WITH ASSOCIATED UNCERTAINTIES.

\begin{tabular}{|l|l|}
\hline \hline Offset Short & \\
\hline Inner conductor diameter $(\mathrm{mm})$ & $1.042 \pm 0.004$ \\
\hline Outer conductor diameter $(\mathrm{mm})$ & $2.400 \pm 0.005$ \\
\hline Outer conductor length $(\mathrm{mm})$ & $6.750 \pm 0.005$ \\
\hline Pin diameter $(\mathrm{mm})$ & $0.511 \pm 0.005$ \\
\hline Offset Load & \\
\hline Inner conductor diameter $(\mathrm{mm})$ & $1.042 \pm 0.004$ \\
\hline Outer conductor diameter $(\mathrm{mm})$ & $2.400 \pm 0.005$ \\
\hline Line length $(\mathrm{mm})$ & $7.700 \pm 0.005$ \\
\hline Load resistance $(\Omega)$ & $50 \pm 0.7$ \\
\hline Load inductance $(\mathrm{nH})$ & $0.02 \pm 0.02$ \\
\hline Pin diameter $(\mathrm{mm})$ & $0.511 \pm 0.005$ \\
\hline Offset Open & \\
\hline Inner conductor diameter $(\mathrm{mm})$ & $1.042 \pm 0.004$ \\
\hline Outer conductor diameter $(\mathrm{mm})$ & $2.400 \pm 0.005$ \\
\hline Line length $(\mathrm{mm})$ & $6.750 \pm 0.005$ \\
\hline Pin diameter $(\mathrm{mm})$ & $0.511 \pm 0.005$ \\
\hline Thru & \\
\hline Inner conductor diameter $(\mathrm{mm})$ & $1.042 \pm 0.004$ \\
\hline Pin diameter $(\mathrm{mm})$ & $0.511 \pm 0.005$ \\
\hline
\end{tabular}

TABLE II

STANDARDS USED FOR THE TRL CALIBRATION WITH AsSOCIATED UNCERTAINTY: W IS THE WIDTH OF THE LINES, H THE THICKNESS OF THE SUBSTRATE, AND L THE LENGTH OF THE LINES. 'C' IS THE LOW-FREQUENCY CAPACITANCE OF THE LINES [27].

\begin{tabular}{|c|c|c|c|}
\hline \hline & $\mathrm{W}(\mu \mathrm{m})$ & $\mathrm{H}(\mu \mathrm{m})$ & $\mathrm{L}(\mu \mathrm{m})$ \\
\hline Line $\left(\mathrm{L}_{1}\right)$ & $48.7 \pm 2$ & $70 \pm 7$ & $3850 \pm 2$ \\
\hline Line $\left(\mathrm{L}_{2}\right)$ & $48.7 \pm 2$ & $70 \pm 7$ & $1200 \pm 2$ \\
\hline Line $\left(\mathrm{L}_{3}\right)$ & $48.7 \pm 2$ & $70 \pm 7$ & $400 \pm 2$ \\
\hline THRU & $48.7 \pm 2$ & $70 \pm 7$ & 0 \\
\hline Reflect & $48.7 \pm 2$ & $70 \pm 7$ & 0 \\
\hline & & & \\
\hline Probe-alignment error & $\pm 5 \mu \mathrm{m}$ & & \\
\hline & \multicolumn{3}{|l}{} \\
\hline $\mathrm{C}=1.953 \mathrm{pF} / \mathrm{cm}$ & \multicolumn{4}{|l}{} \\
\hline
\end{tabular}

TABLE III

NOMinal VAlue and POINT-By-POINT STANDARD UNCERTAINTY OF THE COMb-Generator PhaSe SPECTRUM Characterized With a SAMPling OSCILlOSCOPE [30], [31]. We ALSO INCLUDED Full CORRELATIONS OF ALL UNCERTAINTIES CONSIDERED IN THE CHARACTERIZATION OF THE COMBGENERATOR.

\begin{tabular}{|c|c|}
\hline Frequency $(\mathrm{GHz})$ & Phase (degree) \\
\hline 5 & $173.7 \pm 0.3$ \\
\hline 10 & $167.8 \pm 0.5$ \\
\hline 15 & $162.6 \pm 0.5$ \\
\hline
\end{tabular}




\begin{tabular}{|l|l|}
\hline 20 & $156.6 \pm 0.7$ \\
\hline 25 & $151.8 \pm 0.7$ \\
\hline 30 & $149.2 \pm 0.5$ \\
\hline 35 & $149.4 \pm 0.7$ \\
\hline 40 & $138.2 \pm 0.6$ \\
\hline
\end{tabular}

The uncertainties in Tables I-III propagate to the corrected waves through the equations of the chosen calibration algorithm and are mapped as uncertainties in the error box coefficients. For example, in Fig. 4 we report the nominal value, along with the uncertainty and $95 \%$ confidence interval, of error coefficient $\mathrm{S}_{53}$ which is the transmission term of the error box $S^{\mathrm{B}}$ in Fig. 3b.

The next step consists of propagating the uncertainties in the corrected waves incident on the transistor to the transistor current-source. The nonlinear de-embedding algorithm [33] used to perform this step is described in the following Section.

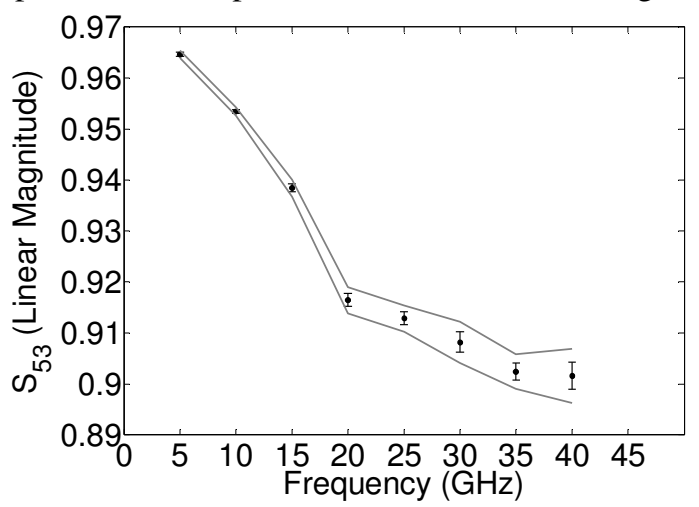

Fig. 4. Standard uncertainty and $95 \%$ confidence interval of the magnitude of the transmission term of error box between $\mathrm{P}_{3}$ and $\mathrm{P}_{5}$.

\section{NONLINEAR DE-EMBEDDING}

With reference to Fig. 1, we define the following vectors,

$$
\begin{aligned}
\underline{V_{m}} h & =\left[\begin{array}{l}
V_{1} \\
V_{2}
\end{array}\right]_{h} \\
\underline{I_{m_{h}}} & =\left[\begin{array}{l}
I_{1} \\
I_{2}
\end{array}\right]_{h} \\
\underline{V_{\text {int }}} & =\left[\begin{array}{l}
V_{3} \\
V_{4}
\end{array}\right]_{h} \\
\underline{I_{\text {int }} h} & =\left[\begin{array}{l}
I_{3} \\
I_{4}
\end{array}\right]_{h},
\end{aligned}
$$

where $h$ is the frequency index. $\underline{V}_{m}$ and $\underline{I_{m}}$ are the voltages and currents at transistor terminals as measured at microwave frequencies and obtained after calibration. The first step of the de-embedding procedure consists of removing the contribution of the linear parasitic network (see Fig. 1) and obtaining the voltages and currents $\underline{V}_{\underline{i n t}}$ and $\underline{I_{\text {int }}}$. The linear parasitic network, whose elements are extracted as in [34], [35] and reported in Table IV, can be described by a $4 \times 4$ frequency dependent $\mathrm{Y}$ parameter matrix which links $\underline{V}_{i n t}$ and $\underline{\underline{I}}_{i n t}$ to $\underline{V}_{m}$ and $\underline{I}_{m}$ by means of (5),

$$
\left[\begin{array}{l}
\frac{I_{m}}{I_{\text {int }}} h
\end{array}\right]=\underline{Y} h\left[\begin{array}{l}
\frac{V_{m}}{V_{\text {int }}} h
\end{array}\right] .
$$

TABLE IV

VALUES OF THE PARASITIC ELEMENTS

\begin{tabular}{|c|c|c|}
\hline \hline $\mathrm{R}_{\mathrm{G}}(\Omega)$ & $\mathrm{R}_{\mathrm{D}}(\Omega)$ & $\mathrm{R}_{\mathrm{S}}(\Omega)$ \\
\hline 1.1 & 0.9 & 0.3 \\
\hline $\mathrm{L}_{\mathrm{G}}(\mathrm{pH})$ & $\mathrm{L}_{\mathrm{D}}(\mathrm{pH})$ & $\mathrm{L}_{\mathrm{S}}(\mathrm{pH})$ \\
\hline 26.2 & 25.6 & 13.8 \\
\hline \hline
\end{tabular}

The intrinsic voltages obtained from (5) are those that control the conductive phenomena and the charge storage within the semiconductor area. The former generate the resistive part of the transistor currents $\left(\underline{i_{R}}\right)$, the latter the displacement currents $\left(\underline{i}_{\underline{C}}\right)$. Therefore,

$\underline{i_{\text {int }}}=\underline{i_{R}}+\underline{i_{C}}$

with

$\underline{i_{R}}=\left[\begin{array}{l}i_{R 1} \\ i_{R 2}\end{array}\right]$

$\underline{i_{C}}=\left[\begin{array}{c}i_{C 1} \\ i_{C 2}\end{array}\right]$.

The second step of the nonlinear de-embedding process consists of computing the vector of displacement currents as a function of the intrinsic voltages (9)

$\underline{i_{C}}=f\left(\underline{v_{\text {int }}}\right)$.

The function $f$ describes the transistor intrinsic capacitances, which are bias-dependent. Therefore, $f$ is typically nonlinear and can be expressed either in the form of a look-up table [34] or by analytical expressions [36]. In this work the value of the capacitances are obtained from the bias-dependent imaginary parts of the Y-parameters derived from measured multibias Sparameters. The displacement currents can be computed by means of harmonic-balance simulations.

Once the vector $i_{\mathrm{c}}$ is known, the resistive currents can be computed at each frequency from large-signal measurements with

$\underline{I}_{h}={\underline{I_{\text {int }}}}_{h}-\underline{I}_{h}$.

Using this procedure we obtain the time-domain waveforms of the transistor resistive currents along with the impedances as seen at the current-generator plane, which are computed from

$Z_{h}^{C G P}=-\left.\frac{V_{4}}{I_{R 2}}\right|_{h}$. 
In this work we kept fixed the elements of the parasitic network. Therefore, the results of (10) and (11) strongly depend on the selection of the function $f(9)$ which is directly linked to the transistor capacitance model. The wrong selection of $f$ has a direct impact on the electrical quantities at the current-generator plane and on their uncertainty, as discussed in the next Section.

\section{UNCERTAINTY ANALYSIS}

This Section is split into three parts: the first focuses on the selection of the capacitance model. The second part deals with the uncertainty propagation to the electrical quantities at the current-generator plane. In the last part the results are discussed.

\section{A. Selection of the intrinsic capacitance model}

We studied a $0.25 \times 300 \mu^{2}$ gallium-arsenide (GaAs) transistor. The transistor was biased at $\mathrm{V}_{\mathrm{GS} 0}=-0.6 \mathrm{~V}$ and $\mathrm{V}_{\mathrm{DS} 0}$ $=6 \mathrm{~V}$. The experimental conditions that we considered are such that the gate Schottky junction, represented with the diode in Fig. 1, is never brought to forward or reverse conduction. Therefore we neglected resistive current $i_{\mathrm{R} 1}$ (Fig. 1). The only resistive current we refer to is that associated with the current source IDs in Fig. 1.

The intrinsic transistor capacitances are extracted from Yparameters derived from multi-bias $\mathrm{S}$-parameter measurements. The bias-dependent values of the capacitances are then stored in a look-up table. The look-up table description, as compared to analytical formulations, is very accurate, as nonlinear capacitances are extracted directly from measurements over a dense grid of bias points. However, the look-up table based description has limited extrapolation capability outside the range of the measurements used for the extraction. In order to prevent extrapolation errors, the experimental temporal waveforms considered in this work are such to fall within the measurement grid of the multi-bias Sparameters. We applied nonlinear de-embedding to the following cases:

1.Linear capacitance model. The values of the intrinsic capacitances are assumed to be constant and equal to the value stored in the table corresponding to the selected biaspoint. For the device considered in this work, these values are: $\mathrm{C}_{\mathrm{GS}}=534 \mathrm{fF}, \mathrm{C}_{\mathrm{GD}}=36 \mathrm{fF}, \mathrm{C}_{\mathrm{DS}}=59 \mathrm{fF}$, and $\mathrm{C}_{\mathrm{m}}=$ $313 \mathrm{fF} . \mathrm{C}_{\mathrm{m}}$ is the transcapacitance [37].

2. Partial nonlinear capacitance model. Full look-up table except that the feedback capacitance $\mathrm{C}_{\mathrm{GD}}$ is neglected.

3. Fully nonlinear capacitance model. No approximations are made and the full look-up table is used.

We performed LSNA measurements with the load impedance at $f_{0}$ and $2 f_{0}$ close to $50 \Omega$. The load impedance at $3 \mathrm{f}_{0}=15 \mathrm{GHz}$ was tuned by active signal injection and we searched for a value close to the edge of the Smith Chart. In this way we could mimic for the third harmonic the situation encountered in the designing high-efficiency amplifiers, where harmonics are terminated with an open or short circuit [15]-
[16]. The value of the measured output impedance $\left(Z_{\mathrm{EXT}}\right)$ at $\mathrm{f}_{0}$, $2 \mathrm{f}_{0}$, and $3 \mathrm{f}_{0}$ is reported in Table $V$. In the same Table, we report the impedances at the intrinsic plane $\left(\mathrm{Z}_{\mathrm{INT}}\right)$ and the impedances at the current-generator plane $\left(Z_{\mathrm{CGP}}\right)$ obtained after performing nonlinear de-embedding with the three transistor capacitance models.

TABLE V

Nominal VALUE OF THE IMPEDANCES AT THE EXTRINSIC Plane AND AT THE CURRENT-GENERATOR PLANE AFTER NONLINEAR DE-EMBEDDING

\begin{tabular}{|c|c|c|c|}
\hline \hline & $\mathrm{f}_{0}(\Omega)$ & $2 \mathrm{f}_{0}(\Omega)$ & $3 \mathrm{f}_{0}(\Omega)$ \\
\hline$Z_{\mathrm{EXT}}$ & $52.2-\mathrm{j} 2.6$ & $53.1-\mathrm{j} 5.9$ & $36.7+\mathrm{j} 373.8$ \\
\hline $\mathrm{Z}_{\mathrm{INT}}$ & $53.3-\mathrm{j} 1.3$ & $54.2-\mathrm{j} 3.3$ & $40.1+\mathrm{j} 373.5$ \\
\hline $\mathrm{Z}_{\mathrm{CGP}, 1}$ & $49.4-\mathrm{j} 18.7$ & $42.0-\mathrm{j} 11.9$ & $29.1-\mathrm{j} 34.7$ \\
\hline $\mathrm{Z}_{\mathrm{CGP}, 2}$ & $51.4-\mathrm{j} 1.1$ & $50.4-\mathrm{j} 10.2$ & $78.6-\mathrm{j} 40.9$ \\
\hline $\mathrm{Z}_{\mathrm{CGP}, 3}$ & $49.3-\mathrm{j} 16.6$ & $40.4-\mathrm{j} 22.4$ & $94.2-\mathrm{j} 117.1$ \\
\hline
\end{tabular}

As expected, the impedances at the current-generator plane strongly depend on the values of the de-embedded transistor capacitances and the nonlinear capacitance model we used. Moreover, each set of de-embedded impedances results in different current and voltage time-domain waveforms at the current-generator plane, as shown in Fig. 5.

In Fig. 5 we report the dynamic voltage-current relationships $\left(i_{4}\right.$ vs $\left.v_{3}\right)$ and loadline $\left(i_{4}\right.$ vs $\left.v_{4}\right)$ corresponding to the impedance $\mathrm{Z}_{\mathrm{INT}}$ in Table $\mathrm{V}$ obtained after de-embedding only the effect of the linear parasitic network. In the same figure we show the dynamic voltage-current relationships $\left(i_{\mathrm{R} 2}\right.$ vs $\left.v_{3}\right)$ and loadline $\left(i_{\mathrm{R} 2}\right.$ vs $\left.v_{4}\right)$ at the current-generator plane after de-embedding the transistor nonlinear capacitances, corresponding to $Z_{\mathrm{CGP}, 1}, Z_{\mathrm{CGP}, 2}$, and $\mathrm{Z}_{\mathrm{CGP}, 3}$ in Table $\mathrm{V}$. $\mathrm{Z}_{\mathrm{CGP}, 1}$, $Z_{\mathrm{CGP}, 2}$, and $\mathrm{Z}_{\mathrm{CGP}, 3}$ are also shown on the Smith chart along with the measured impedance $\mathrm{Z}_{\mathrm{EXT}}$.

If the nonlinear de-embedding is properly performed, the de-embedded resistive current waveform $i_{\mathrm{R} 2}$ must satisfy constraints directly linked to the transistor's physical behavior. First, the current must show clipping at zero amperes when the instantaneous gate-source voltage ( $v_{3}$ in Fig. 1$)$ is smaller than the threshold voltage. Moreover, if the transistor in saturation region behaved as an ideal voltage controlled current-source, voltage-current relationships shown in Fig. $5-i_{\mathrm{R} 2}$ vs $v_{3}$ (a)-(c) - should show almost no hysteresis. This behavior should manifest even if the loadline at the current-source terminals $i_{\mathrm{R} 2}$ vs $v_{4}$ (Fig. 5 (d)-(f)) - was not a closed line. Clearly the actual behavior of the transistor may deviate from that ideal if channel-length modulation and thermal effects are not negligible and may introduce a slight hysteresis in the voltagecurrent relationships in Fig. 5 (a)-(c).

The only dynamic voltage-current relationships ( $i_{\mathrm{R} 2}$ vs $\left.v_{3}\right)$ which reproduces the behavior close to that of a voltage controlled current source is that in Fig. 5c, which corresponds to $\mathrm{Z}_{\mathrm{CGP}, 3}$ (Fig. 5i) and which is obtained by using the fully nonlinear capacitance model. The linear model yields a resistive current waveform which poorly clips to zero amperes in the pinch-off region (Fig. 5a), where the actual capacitance to be de-embedded is smaller than that at the bias-point. When neglecting the feedback capacitance $\left(\mathrm{C}_{\mathrm{GD}}=0 \mathrm{~F}\right)$, significant hysteresis remains in the de-embedded voltage-current 
relationship (Fig. 5b).

Similarly, the wrong selection of the transistor capacitance model affects the time-domain waveform of the gate current, which is purely capacitive in our case and related to $C_{G S}$ and $\mathrm{C}_{\mathrm{GD}}$ in Fig. 1. The measured temporal gate-current waveform is compared in Fig. 6 with the simulations obtained by the three capacitance models. As before, the best agreement is obtained with the fully nonlinear capacitance model.

This analysis, which can be extended to other devices and different technologies, suggests that waveform engineering can be performed, as proposed in [14], if one knows

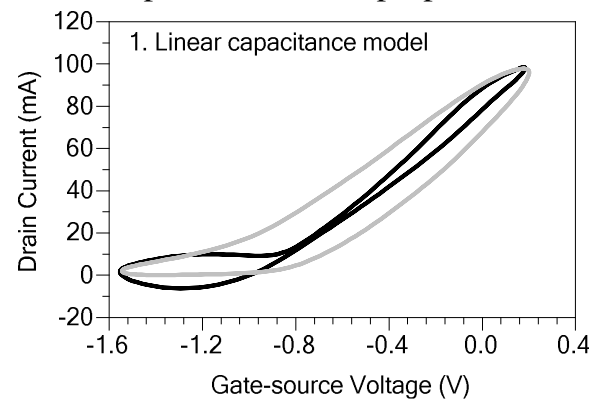

(a)

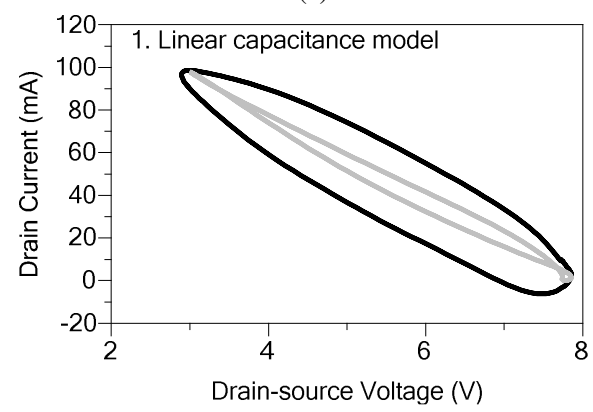

(d)

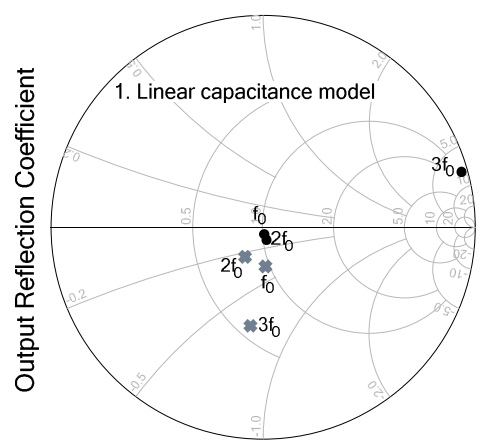

(g)

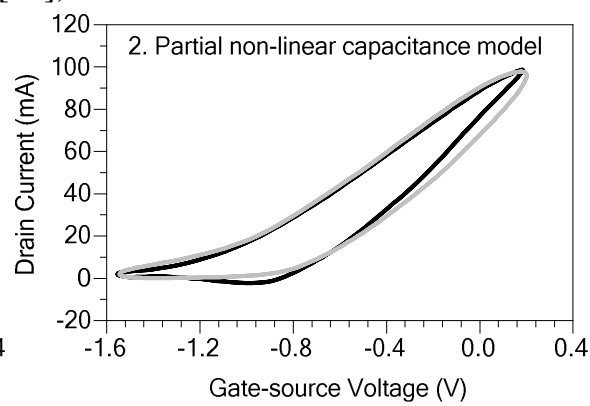

(b)

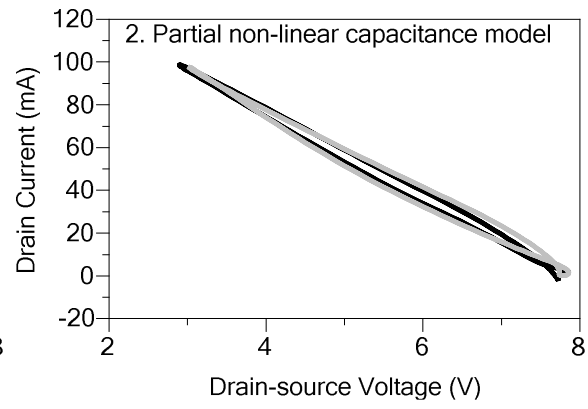

(e)

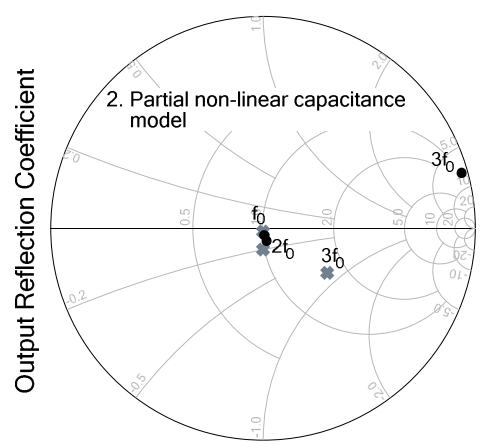

(h)

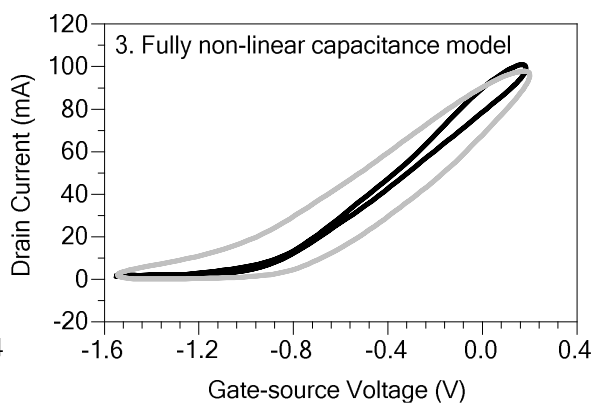

(c)

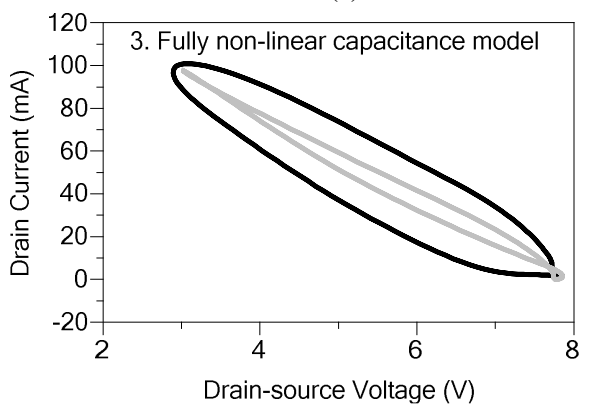

(f)

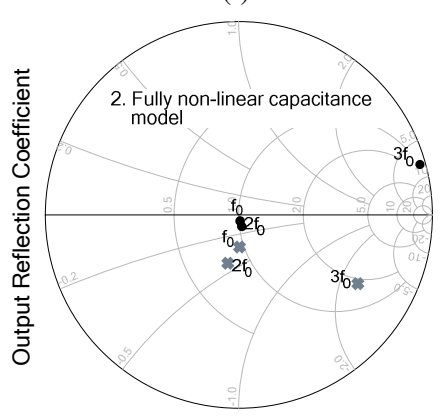

(i)

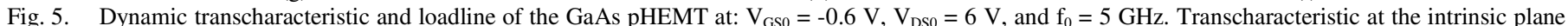

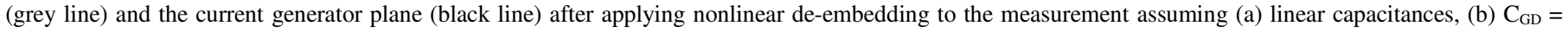

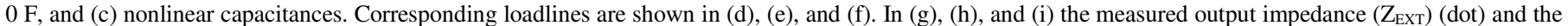
impedance at the current-generator plane obtained after de-embedding (crosses) at $\mathrm{f}_{0}, 2 \mathrm{f}_{0}$, and $3 \mathrm{f}_{0}$.
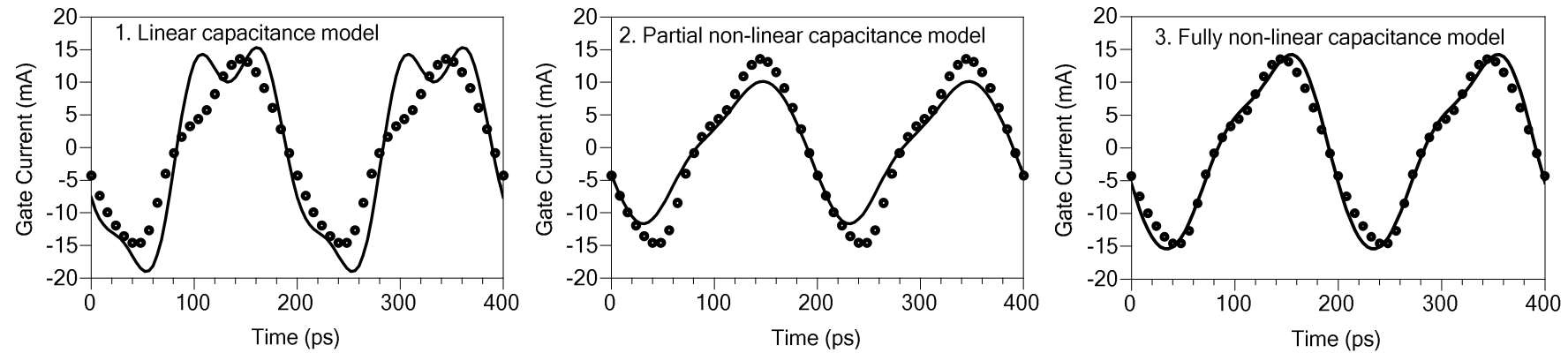
(a)

(b)

(c)

Fig. 6. Measured (symbols) gate current time-domain waveform of the GaAs pHEMT at: $\mathrm{V}_{\mathrm{GS} 0}=-0.6 \mathrm{~V}, \mathrm{~V}_{\mathrm{DS} 0}=6 \mathrm{~V}$, and $\mathrm{f}_{0}=5 \mathrm{GHz}$. The simulated gate current waveform (continuous line) is obtained assuming (a) linear capacitances, (b) $\mathrm{C}_{\mathrm{GD}}=0 \mathrm{~F}$, and (c) nonlinear capacitances.

\section{B. Uncertainty results}

The NIST Microwave Uncertainty Framework performs error analysis based on a sensitivity approach and Monte Carlo method that preserve correlations in the uncertainties [7], [23]. As schematically illustrated in Fig. 7, the uncertainties in the calibration standards are first mapped through the calibration coefficients into the corrected waves at the transistor terminals both in frequency and timedomain. Subsequently, the uncertainties in the corrected waves at the transistor terminals are propagated to the electrical quantities at the transistor current-generator plane. This is accomplished via a post-processor module which is embedded in the Microwave Uncertainty Framework.

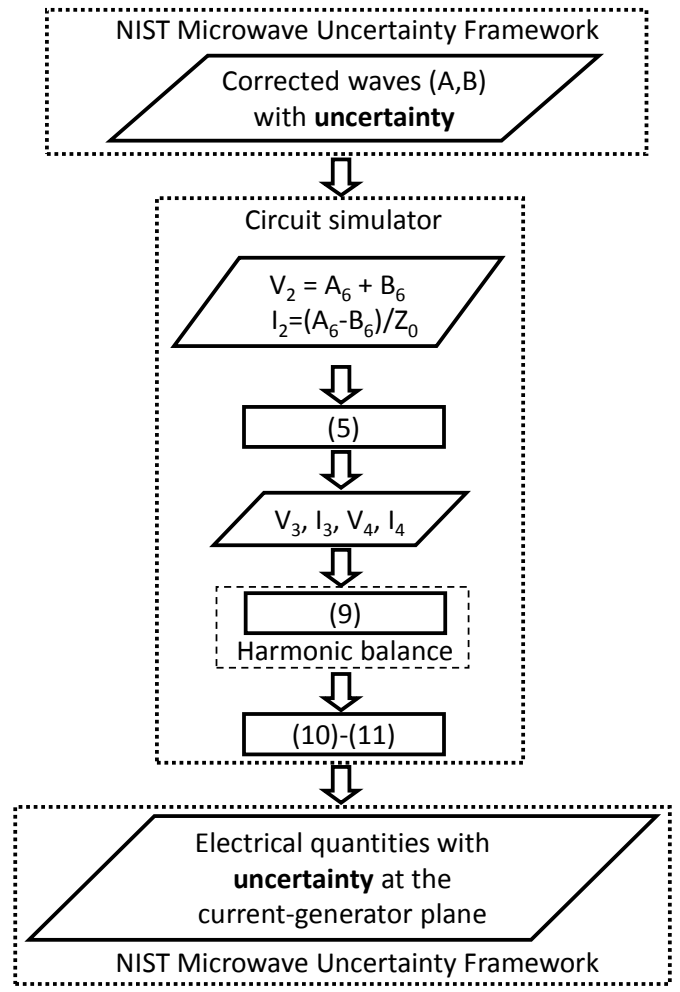

Fig. 7. Microwave Uncertainty Framework and post-processor. The equations of the nonlinear de-embedding and the harmonic-balance analysis are performed with a commercial circuit simulator.

The post-processor module in the Microwave Uncertainty Framework controls a commercial circuit simulator where the equations of the nonlinear deembedding (5), (9)-(11) were implemented and propagates the sensitivity and Monte-Carlo analyses through the circuit simulations. The circuit simulator enabled harmonicbalance analysis, which was needed to evaluate the displacement current generated by the nonlinear capacitances (9).

Along with the sensitivity analysis, which included 394 sources of uncertainty, we performed 100 Monte-Carlo simulations. As previously mentioned, the measurands we focused on are the electrical quantities at the currentgenerator plane.
In Table VI we report the nominal value, standard uncertainty, and confidence interval of the impedances at $\mathrm{f}_{0}$, $2 \mathrm{f}_{0}$, and $3 \mathrm{f}_{0}$. The impedances in Table VI are those at the extrinsic plane (i.e., transistor terminals), at the intrinsic plane (only parasitic network is de-embedded), and the current generator plane. In Fig. 8 we also show the histograms, including Monte-Carlo simulations results, of the impedances at the current-generator plane. Monte-Carlo results confirm the validity of the sensitivity analysis as no significant statistical bias is observed in the expected value.

The individual contributions to the total uncertainty in the impedances at the current-generator plane are reported in Table VII.

Each of the contributions listed in Table VII can be further linked to fundamental error mechanisms, as reported in Table VIII for the TRL calibration, which is the most dominant.

Imperfections in the physical dimensions of the lines affect the characteristic impedance [26] whose uncertainty propagates to the calibrated voltage and current waveforms and then to the impedances derived from them.

From Table VII it also emerges that the uncertainty in the impedances at the current-generator plane is also affected by errors in the absolute calibration. On the other hand the impact of errors in the absolute calibration is zero when looking at the impedance at the extrinsic and intrinsic planes. This can explained as follows. The impedance at the extrinsic and intrinsic plane are calculated either directly from measurements at the same reference plane, i.e. the extrinsic plane, or at the intrinsic plane as a result of a linear transformation (5). In these cases, the ratio of voltage and current is obviously not affected by errors in the absolute calibration. Differently, the impedances at the current-generator plane are derived from (9), (10), (11), which include also a nonlinear transformation applied to the intrinsic voltages due the capacitance nonlinearity (9). This transformation makes the impedances at the currentgenerator plane sensitive also to errors in the absolute calibration.

In Fig. 9 we show the temporal waveforms of the voltage and current at the current-generator plane. As the NIST Microwave Uncertainty Framework keeps track of correlations, we can look also at the uncertainty in timedomain.

TABLE VI

Nominal Value, Standard UnCERTAinty, AND 95\% CONFIDENCE INTERVAL OF THE IMPEDANCE AT THE EXTRINSIC PLANE, AT THE INTRINSIC PLANE, AND AT THE CURRENT-GENERATOR PLANE.

\begin{tabular}{|l|c|c|c|}
\hline & nominal $(\Omega)$ & std. unc. $(\Omega)$ & $95 \%$ interval \\
\hline $\operatorname{Re}\left\{Z^{\mathrm{EXT}}\left(\mathrm{f}_{0}\right)\right\}$ & 52.2 & \pm 1.3 & \pm 2.6 \\
\hline $\operatorname{Im}\left\{\mathrm{Z}^{\mathrm{EXT}}\left(\mathrm{f}_{0}\right)\right\}$ & -2.6 & \pm 0.2 & \pm 0.4 \\
\hline $\operatorname{Re}\left\{\mathrm{Z}^{\mathrm{EXT}}\left(2 \mathrm{f}_{0}\right)\right\}$ & 53.1 & \pm 1.0 & \pm 2.0 \\
\hline $\operatorname{Im}\left\{\mathrm{Z}^{\mathrm{EXT}}\left(2 \mathrm{f}_{0}\right)\right\}$ & -5.9 & \pm 0.5 & \pm 1.0 \\
\hline $\operatorname{Re}\left\{\mathrm{Z}^{\mathrm{EXT}}\left(3 \mathrm{f}_{0}\right)\right\}$ & 36.7 & \pm 6.6 & \pm 13.2 \\
\hline $\operatorname{Im}\left\{\mathrm{Z}^{\mathrm{EXT}}\left(3 \mathrm{f}_{0}\right)\right\}$ & 373.8 & \pm 26.2 & \pm 52.4 \\
\hline & & & \\
\hline $\operatorname{Re}\left\{\mathrm{Z}^{\mathrm{INT}}\left(\mathrm{f}_{0}\right)\right\}$ & 53.3 & \pm 1.3 & \pm 2.6 \\
\hline
\end{tabular}




\begin{tabular}{|l|c|c|c|}
\hline $\operatorname{Im}\left\{Z^{\mathrm{INT}}\left(\mathrm{f}_{0}\right)\right\}$ & -1.3 & \pm 0.2 & \pm 0.4 \\
\hline $\operatorname{Re}\left\{Z^{\mathrm{INT}}\left(2 \mathrm{f}_{0}\right)\right\}$ & 54.2 & \pm 1.0 & \pm 2.0 \\
\hline $\operatorname{Im}\left\{\mathrm{Z}^{\mathrm{INT}}\left(2 \mathrm{f}_{0}\right)\right\}$ & -3.3 & \pm 0.5 & \pm 1.0 \\
\hline $\operatorname{Re}\left\{Z^{\mathrm{INT}}\left(3 \mathrm{f}_{0}\right)\right\}$ & 40.1 & \pm 6.9 & \pm 13.7 \\
\hline $\operatorname{Im}\left\{\mathrm{Z}^{\mathrm{INT}}\left(3 \mathrm{f}_{0}\right)\right\}$ & 373.5 & \pm 25.9 & \pm 51.8 \\
\hline & & & \\
\hline $\operatorname{Re}\left\{\mathrm{Z}^{\mathrm{CGP}}\left(\mathrm{f}_{0}\right)\right\}$ & 49.3 & \pm 0.9 & \pm 2.0 \\
\hline $\operatorname{Im}\left\{\mathrm{Z}^{\mathrm{CGP}}\left(\mathrm{f}_{0}\right)\right\}$ & -16.6 & \pm 0.6 & \pm 1.3 \\
\hline $\operatorname{Re}\left\{\mathrm{Z}^{\mathrm{CGP}}\left(2 \mathrm{f}_{0}\right)\right\}$ & 40.4 & \pm 0.4 & \pm 0.8 \\
\hline $\operatorname{Im}\left\{\mathrm{Z}^{\mathrm{CGP}}\left(2 \mathrm{f}_{0}\right)\right\}$ & -22.4 & \pm 0.8 & \pm 1.5 \\
\hline $\operatorname{Re}\left\{\mathrm{Z}^{\mathrm{CGP}}\left(3 \mathrm{f}_{0}\right)\right\}$ & 94.2 & \pm 6.1 & \pm 15.4 \\
\hline $\operatorname{Im}\left\{\mathrm{Z}^{\mathrm{CGP}}\left(3 \mathrm{f}_{0}\right)\right\}$ & -117.1 & \pm 7.7 & \pm 12.3 \\
\hline
\end{tabular}

\section{Additional discussion}

In Section IV we highlighted the importance of the choice of a proper capacitance model in order to get correctly uncertainties after applying a nonlinear deembedding procedure. Based on the obtained results, some considerations can be made.

We firstly observe that the uncertainty at the extrinsic plane in the impedance at $3 \mathrm{f}_{0}$ is much larger than the uncertainty at $\mathrm{f}_{0}$ and $2 \mathrm{f}_{0}$. This can be intuitively explained considering that at $3 \mathrm{f}_{0}=15 \mathrm{GHz}$, the magnitudes of the measured waves $\mathrm{a}_{6}$ and $\mathrm{b}_{6}$ are almost equal resulting in the impedance at the edge of the Smith chart, as shown in Fig. 6 . Therefore the sensitivity of the impedance to variations of the reflection coefficient $\Gamma=\mathrm{a}_{6} / \mathrm{b}_{6}$ is larger at $15 \mathrm{GHz}$ than at $5 \mathrm{GHz}$ and $10 \mathrm{GHz}$, where the measured impedance is close to $50 \Omega$. In order to show that the measured incident and scattered waves at $3 \mathrm{f}_{0}$ fall well within the dynamic range of the instrument, their measured amplitudes are reported in Fig. 10.
Furthermore we observe that the uncertainties in the impedances at the extrinsic and intrinsic planes are very similar. The largest difference occurs when propagating the uncertainties to the current-generator plane and when the impedance at the measurement plane significantly differs from $50 \Omega$. For the experimental conditions we considered, the impedance at $\mathrm{f}_{0}$ and $2 \mathrm{f}_{0}$ is very close to $50 \Omega$ at the extrinsic plane and its uncertainty does not change much when shifting it up to the current-generator plane. The largest change is observed when shifting the impedance at $3 \mathrm{f}_{0}$ from the extrinsic plane to the current-generator plane.

Therefore, evaluating the uncertainties in the measured extrinsic impedances may not be sufficient to correctly estimate uncertainties in the corresponding impedances at the current-generator plane.

This is important, since the design approaches based on waveform engineering search for the desired operating condition at the current-generator plane by experimentally tuning the impedances at microwave frequencies at the transistor terminals, i.e., the extrinsic plane. In many situations, the impedances needed to obtain the desired performance are very different from the reference impedance. Therefore nonlinear de-embedding is essential not only to correctly determine the impedances at the current-generator plane, but also to correctly know the uncertainty at the current-generator plane.

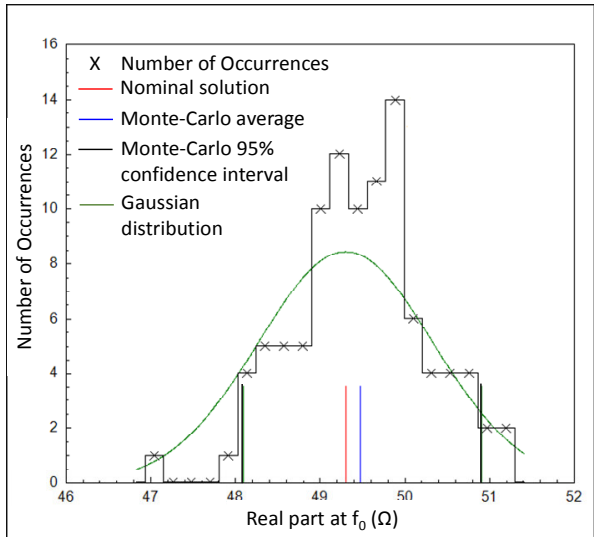

(a)

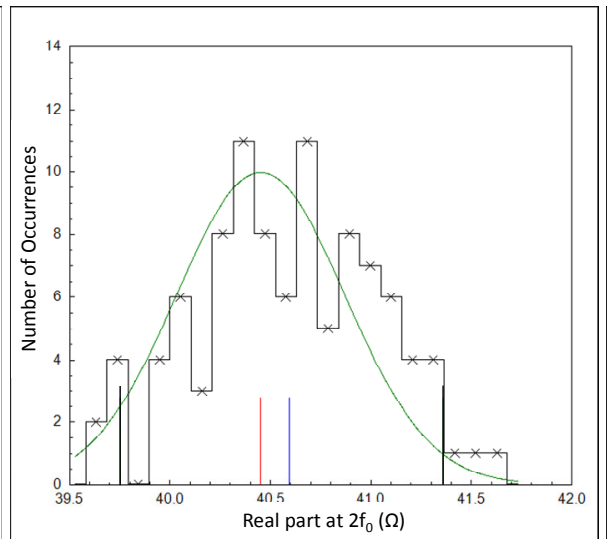

(b)

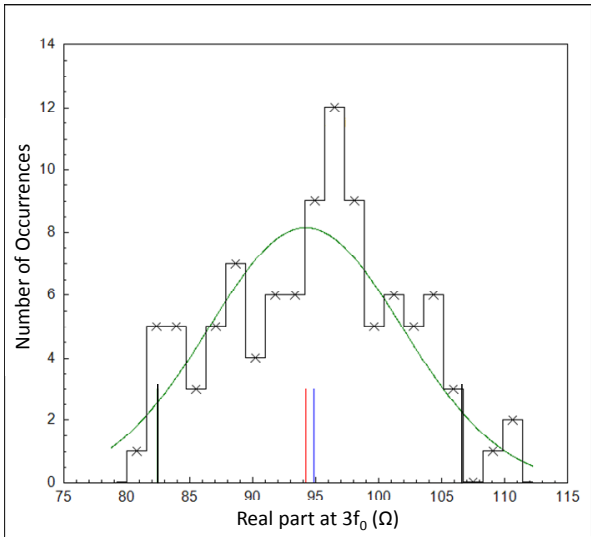

(c) 


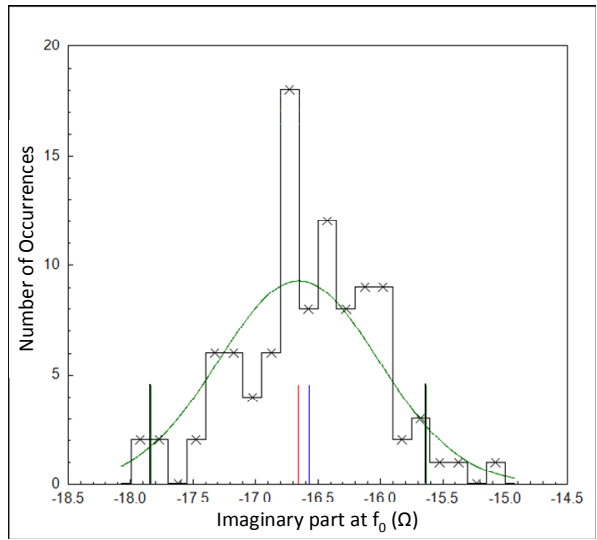

(d)

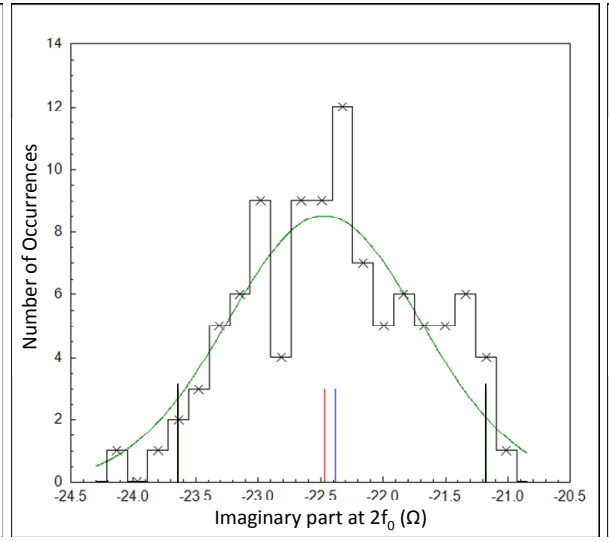

(e)

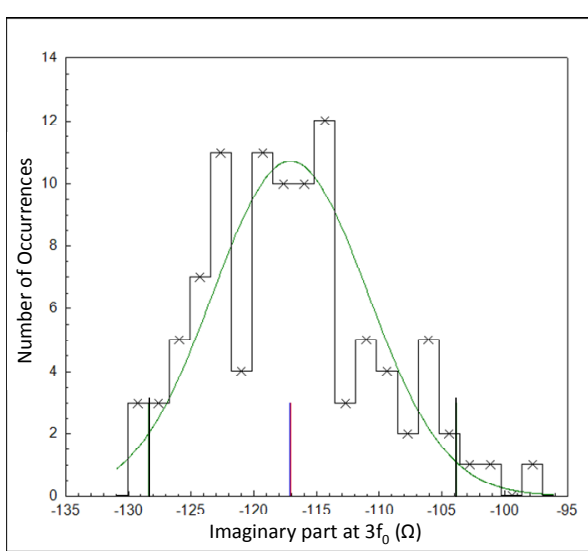

(f)

Fig. 8 Histogram of Monte-Carlo simulations and distribution from sensitivity analysis of the (a)-(c) real and (d)-(f) imaginary part of the load impedance at the current-generator plane at $\mathrm{f}_{0}, 2 \mathrm{f}_{0}$, and $3 \mathrm{f}_{0}$. The blue and the red line (in the color version) are the nominal value and the average from 100 Monte-Carlo simulations respectively.

TABLE VII

COMBINED AND INDIVIDUAL UNCERTAINTY CONTRIBUTIONS IN THE REAL AND IMAGINARY PART OF THE IMPEDANCES AT THE TRANSISTOR CURRENT-

GENERATOR Plane.

\begin{tabular}{|c|c|c|c|c|c|c|}
\hline & $\operatorname{Re}\left\{Z^{\mathrm{CGP}}\left(\mathrm{f}_{0}\right)\right\}(\Omega)$ & $\operatorname{Im}\left\{Z^{\mathrm{CGP}}\left(\mathrm{f}_{0}\right)\right\}(\Omega)$ & $\operatorname{Re}\left\{\mathrm{Z}^{\mathrm{CGP}}\left(2 \mathrm{f}_{0}\right)\right\}(\Omega)$ & $\operatorname{Im}\left\{Z^{\mathrm{CGP}}\left(2 \mathrm{f}_{0}\right)\right\}(\Omega)$ & $\operatorname{Re}\left\{Z^{\mathrm{CGP}}\left(3 \mathrm{f}_{0}\right)\right\}(\Omega)$ & $\operatorname{Im}\left\{Z^{\mathrm{CGP}}\left(3 \mathrm{f}_{0}\right)\right\}(\Omega)$ \\
\hline TOTAL & 1.032 & 0.643 & 0.419 & 0.770 & 7.718 & 6.167 \\
\hline TRL & 1.012 & 0.640 & 0.339 & 0.763 & 7.17 & 5.390 \\
\hline SOLT & 0.001 & 0.001 & 0.010 & 0.006 & 0.563 & 0.480 \\
\hline POWER METER & 0.014 & 0.002 & 0.084 & 0.081 & 1.328 & 2.394 \\
\hline $\begin{array}{c}\text { COMB-GENERATOR } \\
\text { REPEATABILITY }\end{array}$ & 0.002 & 0.001 & 0.012 & 0.004 & 0.698 & 0.697 \\
\hline $\begin{array}{l}\text { COMB-GENERATOR } \\
\text { CHARACTERIZATION }\end{array}$ & 0.002 & 0.001 & 0.024 & 0.015 & 1.559 & 1.342 \\
\hline PROBE ALIGNMENT & 0.203 & 0.060 & 0.212 & 0.046 & 0.805 & 0.505 \\
\hline CABLE BENDING & 0.001 & 0.001 & 0.002 & 0.232 & 0.114 & 0.232 \\
\hline
\end{tabular}

TABLE VIII

COMBINED AND INDIVIDUAL UNCERTAINTY CONTRIBUTIONS IN THE REAL AND IMAGINARY PART OF THE IMPEDANCES AT 3F $\mathrm{F}_{0}$ AT THE TRANSISTOR CURRENTGENERATOR PLANE.

\begin{tabular}{|l|c|c|c|c|c|c|c|}
\hline & $\mathrm{W}\left(\mathrm{L}_{1}\right)$ & $\mathrm{H}\left(\mathrm{L}_{1}\right)$ & $\mathrm{W}\left(\mathrm{L}_{2}\right)$ & $\mathrm{H}\left(\mathrm{L}_{2}\right)$ & $\mathrm{W}$ (Reflect) & $\mathrm{H}$ (Reflect) & TOTAL \\
\hline $\operatorname{Re}\left\{\mathrm{Z}^{\mathrm{CGP}}\left(3 \mathrm{f}_{0}\right)\right\}(\Omega)$ & 2.026 & 5.321 & 0.855 & 2.201 & 2.559 & 2.559 & 7.718 \\
\hline $\operatorname{Im}\left\{\mathrm{Z}^{\mathrm{CGP}}\left(3 \mathrm{f}_{0}\right)\right\}(\Omega)$ & 2.150 & 4.542 & 0.703 & 1.703 & 0.364 & 0.524 & 6.167 \\
\hline
\end{tabular}

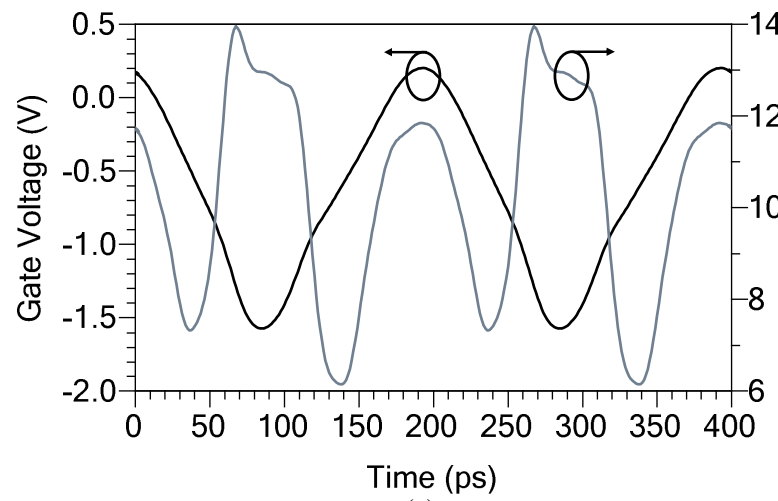

(a)

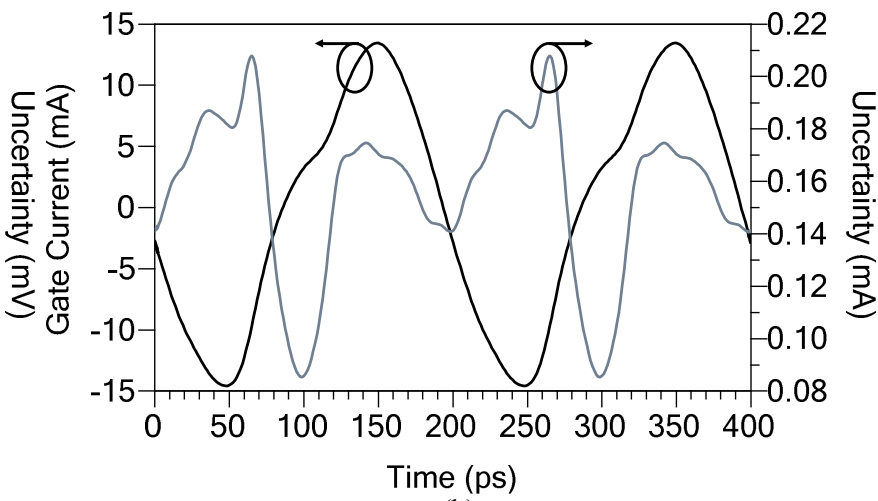

(b) 


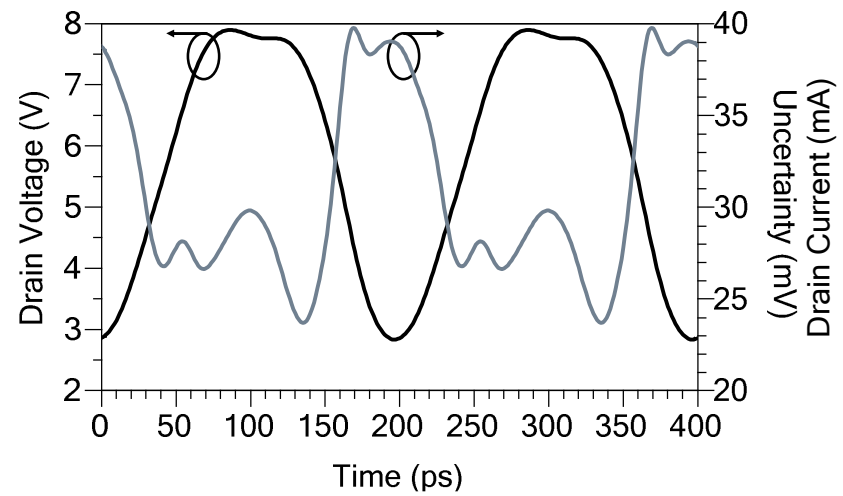

(c)

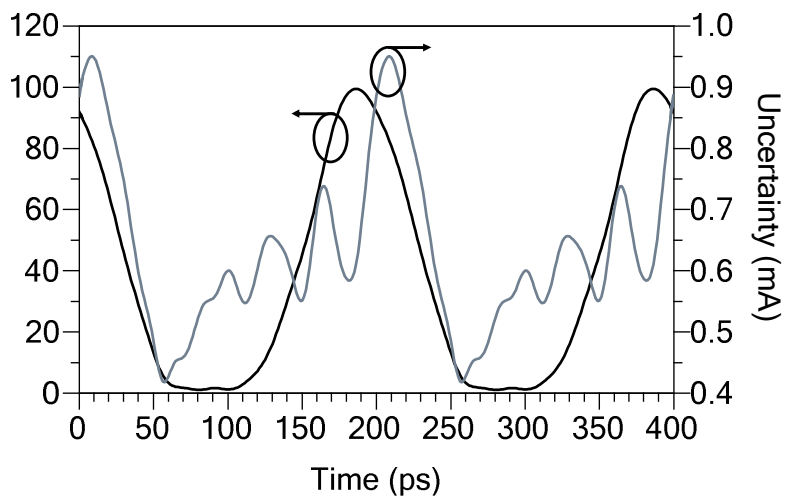

(d)

Fig. 9. (a) Gate voltage, (b) gate current, (c) drain voltage, and (d) drain current time-domain waveforms at the current-generator plane at $\mathrm{V}_{\mathrm{GS} 0}=-0.6 \mathrm{~V}, \mathrm{~V}_{\mathrm{DS} 0}=$ $6 \mathrm{~V}, \mathrm{f}_{0}=5 \mathrm{GHz}$, input power equal to $6 \mathrm{dBm}, \mathrm{Z}_{\mathrm{CGP}}\left(\mathrm{f}_{0}\right)=49.3-\mathrm{j} 16.6 \Omega, \mathrm{Z}_{\mathrm{CGP}}\left(2 \mathrm{f}_{0}\right)=40.4-\mathrm{j} 22.4 \Omega, \mathrm{Z}_{\mathrm{CGP}}\left(3 \mathrm{f}_{0}\right)=94.2-\mathrm{j} 117.1 \Omega$. Nominal solution (black line) and standard uncertainty (grey line).

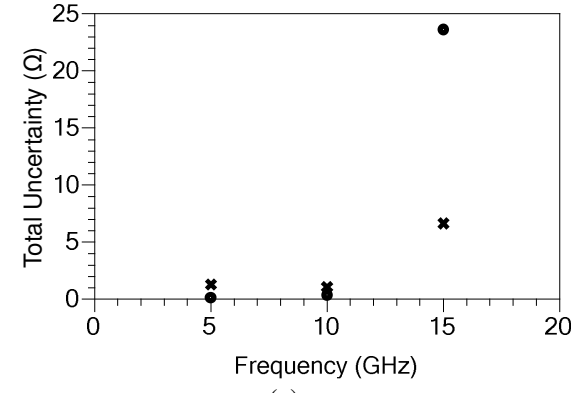

(a)

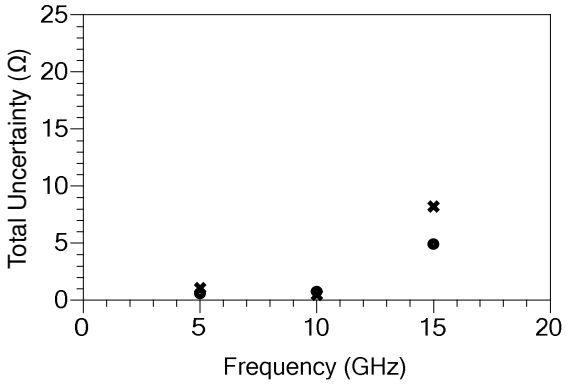

(b)

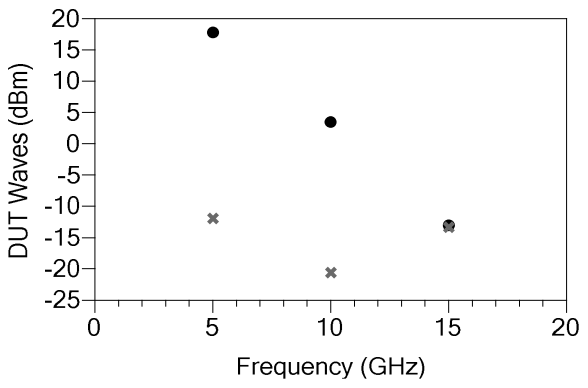

(c)

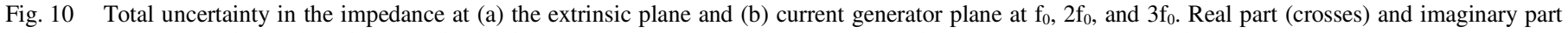
(circles). In (c) the nominal value of the amplitude of the corrected waves $\mathrm{a}_{6}$ (crosses) and $\mathrm{b}_{6}$ (circles) at the transistor terminals.

\section{CONCLUSION}

We evaluated the uncertainties in on-wafer vectorcalibrated nonlinear measurements with the NIST Microwave Uncertainty Framework. The residual uncertainties in the calibration procedure were first propagated to the temporal voltage and current waveforms at the transistor terminals. Next we propagated the uncertainties in the calibrated waves at the transistor terminals to the temporal current and voltage waveforms and the impedances at the transistor currentgenerator plane. These electrical quantities, which represent the measurands of our analysis, cannot be measured directly at microwave frequencies as they are masked by the transistor's parasitic network and intrinsic nonlinear capacitances. A nonlinear de-embedding procedure is therefore needed if one wants to correctly retrieve the current-generator plane electrical quantities with their uncertainty.

We included in our analysis uncertainties in the passive calibration standards, power meter, NIST traceable phase calibration reference, cable bending, and probe alignment.

Other sources of uncertainties can be added in a straightforward manner.

\section{REFERENCES}

[1] Y. Rolain, W. Van Moer, G. Vandersteen, and J. Schoukens, "Why are nonlinear microwave systems measurements so involved," IEEE Trans. Instr. Meas., vol. 53, no. 3, pp. 726-729, Jun. 2004.

[2] U. Lott, "Measurement of magnitude and phase of harmonics generated in nonlinear microwave two-ports," IEEE Trans. Microw. Theory Techn., vol. 37, no. 10, pp. 1506-1511, Oct. 1989.
[3] G. Kompa and F. Van Raay, "Error-corrected large-signal waveform measurement system combining network analyzer and sampling oscilloscope capabilities," IEEE Trans. Microw. Theory Techn., vol. 38, no. 4, pp. 358-365, Apr. 1990.

[4] T. Van den Broek and J. Verspecht, "Calibrated vectorial nonlinearnetwork analyzers," IEEE MTT-S International Microwave Symposium Digest, vol.2, pp. 1069-1072, May 1994.

[5] P. S. Blockley, D. Gunyan, and J. B. Scott, "Mixer-based, vectorcorrected, vector signal/network analyzer offering $300 \mathrm{kHz}-20 \mathrm{GHz}$," IEEE MTT-S Int. microw. Symp. Dig., pp. 1497-1500, June 2005.

[6] M. Marchetti, J.M. Pelk, K. Buisman, W. Neo, M. Spirito, and L.C.N. de Vreede, "Active harmonic load-pull with realistic wideband communications signals," IEEE Trans. Microw. Theory Techn., vol. 56, no. 12 , pp. 2979-2988, Dec. 2008.

[7] A. Lewandowski, D. Williams, P. Hale, C. M. Wang, and A. Dienstfrey, "Covariance-matrix-based vector-network-analyzer uncertainty analysis for time-and frequency-domain measurements," IEEE Trans. Microw. Theory Techn., vol. 58, no. 7, pp. 1877-1866, Jul. 2010.

[8] M. Garelli and A. Ferrero, "A unified theory for S-parameter uncertainty evaluation," IEEE Trans. Microw. Theory Techn., vol. 60, no. 12, pp. 3844-3855, Dec. 2012.

[9] A. Arsenovic, L. Chen, M.F. Bouwens, H. Li, N.S. Barker, and R.M. Weikle, "An experimental technique for calibration uncertainty analysis," IEEE Trans. Microw. Theory Techn., vol. 61, no. 1, pp. 263269, Jan. 2013

[10] V. Teppati and A. Ferrero, "A Comparison of uncertainty evaluation methods for on-wafer S-parameter measurements," IEEE Trans. Instr. Meas., vol. 63, no. 4, pp. 935-942, Apr. 2014.

[11] V. Teppati, S. Tirelli, R. Lövblom, R. Fluckiger, M. Alexandrova, and C. R. Bolognesi, "Accuracy of microwave transistor fT and fMAX extractions," IEEE Trans. Electr. Dev., vol. 61, no. 4, pp. 984-999, Apr. 2014.

[12] A. Ferrero, V. Teppati, and A. Carullo, "Accuracy evaluation of onwafer load-pull measurements," IEEE Trans. Microw. Theory Techn., vol. 49, no. 1, pp. 39-43, Jan. 2001.

[13] V. Teppati and C.R. Bolognesi, "Evaluation and reduction of calibration residual uncertainty in load-pull measurements at millimeter-wave frequencies," IEEE Trans. Instr. Meas., vol. 61, no. 3, pp. 817-822, Mar. 2012. 
[14] P.J. Tasker, "Practical waveform engineering," IEEE Microw. Magazine, vol. 10, no. 7, pp. 65-76, Dec. 2009.

[15] P. Colantonio, F. Giannini, E. Limiti, V. Teppati, "An approach to harmonic load- and source-pull measurements for high-efficiency PA design," IEEE Trans. Microw. Theory and Techn., vol. 52, no. 1, pp. 191-198, Jan. 2004.

[16] S.C. Cripps, RF Power Amplifiers for Wireless Communication, Second Edition.

[17] H. Jang, P. Roblin, and Z. Xie, "Model-based nonlinear embedding for power amplifiers design," IEEE Trans. Microw. Theory and Techn., vol. 62, no. 9, pp. 1986-2002, Sept. 2014.

[18] A. Raffo, G. Bosi, V. Vadalà, and G. Vannini, "Behavioral modeling of GaN FETs: a load-line approach," IEEE Trans. Microw. Theory and Techn., vol. 62, no. 1, pp. 73-82, Jan. 2014.

[19] A. Werthof, F. van Raay, and G. Kompa, "Direct nonlinear power MESFET parameter extraction and consistent modeling," in Proc. IEEE MTT-S Microwave Symposium, vol. 2, pp. 645-648, Jun. 1993.

[20] A. Raffo, G. Avolio, D. Schreurs, S di Falco, V. Vadalà, F. Scappaviva, G. Crupi, and B. Nauwelaers, "On the evaluation of the high-frequency load-line in active devices," Int. Journ. of Microw. Wireless Tech., vol. 3, no. 1, pp. 19-24, Jan. 2011.

[21] G. Avolio, D. Schreurs, A. Raffo, G. Vannini, and B. Nauwelaers, "Waveforms-only based nonlinear de-embedding in active devices," IEEE Microw. Wireless Compon. Lett. , vol. 22, no. 4, pp. 215-217, Apr. 2012.

[22] D. Rytting, "Network analyzer error models and calibration methods." White Paper, Sept. 1998, Hewlett-Packard Company.

[23] D. F. Williams, A. Lewandowski, T.S. Clement, C.M. Wang, P. Hale, J.M. Morgan, D.A. Keenan, and Dienstfrey, "Covariance-based uncertainty analysis of the NIST electroptic sampling system," IEEE Trans. Microw. Theory Techn., vol. 54, no. 1, pp. 481-491, Jan. 2006.

[24] A. Ferrero and U. Pisani, "An Improved Calibration Technique for OnWafer Large-Signal Transistor Characterization," IEEE Trans. Instr. Meas Tech., vol. 42, no. 2, pp. 360-364, Apr. 1993.

[25] R.B. Marks, "A multi-line method of network analyzer calibration," IEEE Trans. Microw. Theory Techn., vol. 39, no. 7, pp. 1205-1215, Jan. 1991

[26] R.B. Marks and D.F. Williams, "Characteristic impedance determination using propagation constant measurement," IEEE Microw. Guided Wave Letters, vol. 1, no. 6, pp. 141-143, June 1991.

[27] D. F. Williams and R. B. Marks, "Transmission Line Capacitance Measurement," IEEE Microw. Guided Wave Letters, vol. 1, no. 9, pp. 243-245, Sept. 1991.

[28] P.S. Blockley, J.B. Scott, D. Gunyan, and A.E. Parker, "The random component of mixer-based nonlinear vector network analyzer measurement uncertainty," IEEE Trans. Microw. Theory Techn., vol. 55, no. 10, pp. 131-155, Dec. 2002.

[29] IEEE Standard for Precision Coaxial Connectors (DC to $110 \mathrm{GHz}$ ), IEEE Standard 287-2007 (revision of IEEE Standard 287-1968), 2007, pp. C1-119-21.

[30] H. C. Reader, D. F. Williams, P. D. Hale, and T. S. Clement, "Characterization of a $50 \mathrm{GHz}$ comb generator," IEEE Trans. Microwave Theory Techn., vol. 56, no. 2, pp. 515-521, Feb. 2008.

[31] P. D. Hale, A. Dienstfrey, C. M. Wang, D. F. Williams, A. Lewandowski, D. A. Keenan, and T. S. Clement, "Traceable waveform calibration with a covariance-based uncertainty analysis," IEEE Trans. Instrum. Meas., vol. 58, no. 10, pp. 3554-3568, Oct. 2009.

[32] Fundamentals of RF and Microwave Power Measurements (Part 3), Keysight Technologies, application note.

[33] A. Raffo, V. Vadalà, and G. Vannini "Nonlinear embedding and deembedding: theory and applications," Chapter 9 in the book "Microwave de-embedding: from theory to application," edited by G. Crupi and D. M. M.-P. Schreurs, Oxford:UK: Academic Press, 2014.

[34] G. Crupi, D. M. M.-P. Schreurs, D. Xiao, A. Caddemi, B. Parvais, A. Mercha, and S. Decoutere, "Determination and validation of new nonlinear FinFET model based on lookup tables," IEEE Microw. Wireless Compon. Lett., vol. 17, no. 5, pp. 361-363, May 2007.

[35] G. Dambrine, A. Cappy, F. Heliodore, and E. Playez, "A new method for determining the FET small-signal equivalent circuit," IEEE Trans. Microw. Theory Techn., vol. 36, no. 7, pp. 1151-1159, Jul. 1988.

[36] I. Angelov, N. Rorsman, J. Stenarson, M. Garcia, and H. Zirath, "An empirical table-based FET model," IEEE Trans. Microw. Theory and Techn., vol. 47, no. 12, pp. 2350-2357, Dec. 1999.

[37] D.E. Root, "Nonlinear charge modeling for FET large-signal simulation and its importance for IP3 and ACPR in communication circuits," in
Proc. of the $44^{\text {th }}$ IEEE Midwest Symp. on Circuits and Systems (MWSCAS), vol. 2, pp. 768-772, Aug. 2001.

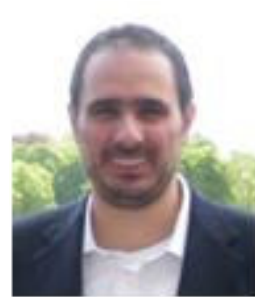

Gustavo Avolio was born in Cosenza, Italy, in 1982. $\mathrm{He}$ received the MSc. in electronic engineering from the University of Calabria, Italy, in 2006. In 2012 he obtained the $\mathrm{PhD}$ in electronic engineering from $\mathrm{KU}$ Leuven, Belgium. He is currently a post-doctoral researcher supported by FWO Vlaanderen Belgium. $\mathrm{He}$ has been a Visiting Scientist with the University of Ferrara, Italy, in 2009, 2011, and 2014. In 2013 and 2014 he has been a Visiting Scientist with the National Institute of Standards and Technology (NIST), Boulder, Colorado. His research work focuses on large-signal measurements and nonlinear modeling of active microwave devices.

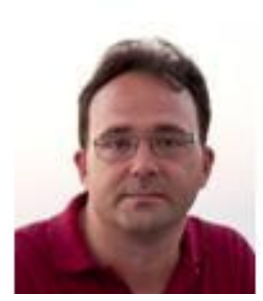

Antonio Raffo (S'04-M'07) was born in Taranto, Italy, in 1976. He received the M.S. degree in electronic engineering (with honors) and Ph.D. degree in information engineering from the University of Ferrara, Italy, in 2002 and 2006, respectively.

Since 2002, he has been with the Engineering Department, University of Ferrara, where he is currently a Research Associate and teaches courses in semiconductor devices and electronic instrumentation and measurement. He has coauthored over 100 publications in international journals and conferences. His research activity is mainly oriented to nonlinear electron device characterization and modeling and circuit-design techniques for nonlinear microwave and millimeter-wave applications.

Dr. Raffo is a member of the IEEE MTT-11 Technical Committee. He serves as Associate Editor of the International Journal of Numerical Modelling: Electronic Networks, Devices and Fields. He also served as Technical Program Chair for the IEEE International Workshop on Integrated Nonlinear Microwave and Millimetre-wave Circuits (INMMiC), Leuven, Belgium, 2014.

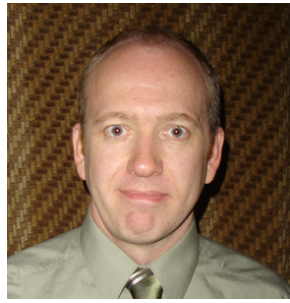

Jeffrey Jargon received the B.S., M.S., and $\mathrm{Ph} . \mathrm{D}$. degrees in electrical engineering from the University of Colorado at Boulder in 1990, 1996, and 2003, respectively. He has been a Staff Member of the National Institute of Standards and Technology (NIST), Boulder, CO, since 1990 and has conducted research in the areas of vector network analysis, optical performance monitoring, and waveform metrology. $\mathrm{He}$ is presently a member of the High-Speed Measurements Group in the Communications Technology Laboratory. Jeffrey was the recipient of four best paper awards, an URSI Young Scientist Award, and a Department of Commerce Silver Medal Award. He is a Senior Member of IEEE, a registered Professional Engineer in the State of Colorado, and an ASQ Certified Quality Engineer.

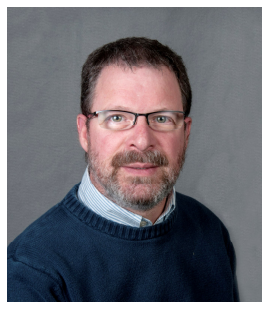

Paul D. Hale (M '01-SM '01-F'15) received a Bachelor of Science degree in Engineering Physics in 1985 and Doctor of Philosophy degree in Applied Physics in 1989, both from the Colorado School of Mines, Golden, $\mathrm{CO}$. $\mathrm{He}$ was with the Optoelectronics Division of the National Institute of Standards and Technology (NIST), Boulder, CO, from 1989 until 2014, where he conducted research on broadband optoelectronic device and signal metrology. He is now Leader of the High-Speed Measurements Group in the RF Technology Division of NIST's newly created Communications Technology Laboratory. Current technical work focuses on implementing a covariance-based uncertainty analysis that can be used for both time- and frequency-domain quantities of interest for wireless communications and disseminating NIST traceability through high-speed electronic and optoelectronic measurement services. Dr. Hale was an Associate Editor of Optoelectronics/Integrated optics for the IEEE Journal of 
Lightwave Technology from June 2001 till March 2007. He has authored or coauthored over 70 technical publications and received the Department of Commerce Bronze, Silver, and Gold Awards, the Allen V. Astin Measurement Science Award, two ARFTG Best Paper Awards, and the NIST Electrical Engineering Laboratory's Outstanding Paper Award.

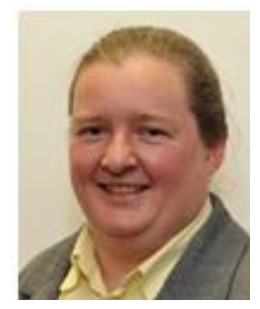

Dominique M. M.-P. Schreurs (S'90-M'97-SM'02Fellow) received the M.Sc. degree in electronic engineering and $\mathrm{Ph} . \mathrm{D}$. degree from the University of Leuven (KU Leuven), Belgium.

She is currently a Full Professor with KU Leuven. She has been a Visiting Scientist with Agilent Technologies, Eidgenössische Technische Hochschule Zürich (ETH Zürich), and the National Institute of Standards and Technology (NIST). Her main research interests concern the (non)linear characterization and modeling of active microwave devices, and (non)linear circuit design for telecommunications and biomedical applications.

Prof. Schreurs is serving on the AdCom of the MTT Society. She is an IEEE Fellow and MTT Distinghuished Microwave Lecturer. She is editor of IEEE Trans. Microwave Theory and Techniques, and past chair of the MTT-S Educational Committee. She also serves on the Executive Committee of the ARFTG organization, and was general chair of the 2007 and 2012 Spring ARFTG Conference. She was also co-chair of the European Microwave Conference (EuMC) in 2008.

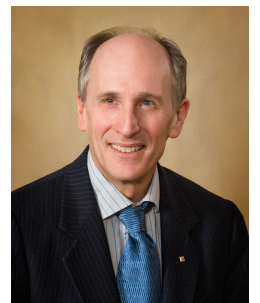

Dylan Williams (M'80-SM'90-F'02) received a Ph.D. in Electrical Engineering from the University of California, Berkeley in 1986. He joined the Electromagnetic Fields Division of the National Institute of Standards and Technology in 1989 where he develops electrical waveform and microwave metrology. He has published over 100 technical papers and is a Fellow of the IEEE. He is the recipient of the Department of Commerce Bronze and Silver Medals, the Astin Measurement Science Award, two Electrical Engineering Laboratory's Outstanding Paper Awards, three Automatic RF Techniques Group (ARFTG) Best Paper Awards, the ARFTG Automated Measurements Technology Award, the IEEE Morris E. Leeds Award, the European Microwave Prize and the 2013 IEEE Joseph F. Keithley Award. Dylan also served as Editor of the IEEE Transactions on Microwave Theory and Techniques from 2006 to 2010 and as the Executive Editor of the IEEE Transactions on Terahertz Science and Technology. 